\title{
Breves consideraciones sobre la regulación del informe en el Proyecto de Ley del Procedimiento Administrativo Común de las Administraciones Públicas
}

\author{
César Cierco Seira \\ Universidad de Lleida \\ cesar@dpub.udl.cat
}

Los principales problemas que plantea la regulación del informe como uno de los trámites centrales en la inteligencia del procedimiento administrativo aparecen en tres frentes cuya regulación es muy desigual en el Proyecto de Ley del Procedimiento Administrativo Común de las Administraciones Públicas (2015).

El primer frente es el que atañe al subprocedimiento de informe, es decir, a la tramitación que ha de seguirse en la elaboración de un informe antes de que éste se inserte, como elemento de juicio, en el correspondiente procedimiento administrativo. Cómo ha de elaborarse un informe y qué consecuencias se siguen de las posibles desviaciones en su confección es asunto que el Proyecto apenas aborda, dejando que sea la normativa organizativa propia del órgano consultado - o la norma sectorial — la que se encargue de fijar, en su caso, las pautas a seguir. No hay novedades en este apartado y el continuismo con la LRJAP es claro. Así, el Proyecto únicamente se preocupa del plazo de evacuación del informe, conservándose a tal efecto el plazo supletorio de diez días; plazo que entrará en juego «salvo que una disposición o el cumplimiento del resto de los plazos del procedimiento permita o exija otro plazo mayor o menor» (art. 80.2). Por otra parte, se obliga a que la forma de emisión de los informes sea electrónica, pensando, claro está, en que tal circunstancia agilice el trámite y esté a tono con el actual signo de los tiempos.

Precisamente en íntima conexión con lo que acaba de decirse, el segundo frente de los informes se sitúa en la obligación de informar en plazo y el tratamiento de las consecuencias de la extemporaneidad. La emisión tardía de un informe debiera ser, en buenos principios, una situación rara y excepcional pero la realidad demuestra que en ocasiones el informe no llega en plazo y sobre la mesa del instructor aparece el dilema de qué hacer. Para hacer frente a esta eventualidad el Proyecto parte de la posibilidad de suspender el plazo para resolver el procedimiento siempre que, eso sí, estemos ante un informe preceptivo (art. 80.3). Esta suspensión, que no es automática, tendrá en todo caso una duración máxima de 3 meses, transcurridos los cuales «proseguirá el procedimiento» (art. 22.1.d in fine).

En apariencia, la solución puede parecer similar a la actualmente vigente. Sin embargo, hay algunos cambios de relieve. En primer lugar, es importante advertir que desaparece la enigmática figura del informe determinante, que hoy queda a caballo entre el informe vinculante y el informe preceptivo, y que introduce claroscuros acerca de la virtualidad real de los informes - ¿qué informe se quiere para sí menos trascendente?-. La desaparición de este tertitum genus nos devuelve a la tradicional clasificación de los informes. Ahora bien, no me resisto a significar que el Proyecto da pie a lo que puede convertirse en una nueva fuente de discusión sobre los confines del informe. $Y$ es que en la nueva regulación del expediente administrativo se hace alusión a los informes internos que, al igual que las notas, borradores, opiniones, resúmenes o comunicaciones, quedarán fuera del mismo, por lo que habrá que aplicarse en definir con tino los contornos de esta especie (art. 70.4). En segundo lugar, se aclara la secuencia de la reacción ante un informe que no llega: cabe la suspensión del plazo máximo para resolver con el límite de tres meses y luego hay que seguir. Desaparece así esa posibilidad de interrumpir la tramitación que contempla hoy el art. 83.3 de la LRJAP («se podrá interrumpir el plazo de los trámites sucesivos»).

Con sendos cambios la regulación gana, sin duda, en claridad. Ahora bien, en mi opinión, queda por resolver todavía el dilema de fondo. Porque preterir el informe extemporáneo puede provocar un vacío instructor primando la celeridad sobre la objetividad. Me resulta difícil imaginar, por ejemplo, que, allí donde el informe está llamado a incorporar un juicio de carácter técnico y se produce una demora, pueda adoptarse una solución cabal sin más. 
Algo así como reconocer la posibilidad de resolver sin pleno conocimiento de causa, lo cual choca frontalmente con el recto entendimiento del principio de objetividad. El Proyecto debería ofrecer alguna solución acerca de cómo rellenar un tal vacío.

Finalmente, en este repaso fugaz, ha de notarse que no se producen avances en la regulación de los vicios procedimentales, lo que afecta, claro está, a los informes. De nuevo se deja toda esta temática trascendental en manos de una fórmula que sigue encerrando un misterio: «el defecto de forma sólo determinará la anulabilidad cuando el acto carezca de los requisitos formales indispensables para alcanzar su fin o dé lugar a la indefensión de los interesados» (art. 48.2). Por tanto, seguirá siendo un ejercicio bien complejo determinar cuál ha de ser la valoración que merezca en términos de invalidez la adopción de una resolución prescindiendo de un informe que, a pesar de ser preceptivo, no fue debidamente incorporado a la instrucción o lo fue irregularmente. 